\title{
La Junta Nacional contra el analfabetismo (1950-1970): un análisis documental
}

\section{The National Committee against the illiteracy (1950-1970): a documentary analysis}

\author{
Alba María López Melgarejo ${ }^{1}$ \\ albalopezmelgarejo@gmail.com \\ Universidad de Murcia, España
}

\section{Resumen:}

El 10 de marzo de 1950 se creaba por decreto la Junta Nacional contra el Analfabetismo cuyo objetivo era reducir la tasa de analfabetos entre la población adulta española a través de una red de juntas provinciales, municipales y locales. El objetivo de este estudio es reconstruir la trayectoria acometida por esta institución durante la década de los cincuenta y sesenta a partir de los documentos publicados en el Boletín Oficial del Estado que hacen mención a la misma.

Encontramos dos momentos claves durante la vigencia de la Junta Nacional. El primero de creación y desarrollo de 1950 a 1963 y un segundo momento definido por la Campaña Nacional contra el Analfabetismo iniciada en 1963 para cuatro cursos escolares. Los esfuerzos de este organismo junto a los realizados por otras instituciones redujeron la tasa de analfabetos adultos de un $17 \%$ en 1950 a un $9 \%$ existente al inicio de 1970.

\section{Palabras clave:}

Junta Nacional; Franquismo; analfabetismo; educación de adultos; alfabetización.

\begin{abstract}
:
On the tenth of March in 1950 The National Committee Against Illiteracy was created by decree with a view to reducing the illiteracy rate among the Spanish adult population. The aim of this study is to reconstruct, from the documents published in the National State Journal, the process followed by this institution during the 1950s and 1960s. We found two keys moments during the enforcement of the National Committee: a period of creation and development from 1950 to 1963 and the activation in 1963 of the National Campaign Against Illiteracy which lasted for four school years. The efforts of this organization along with those by other institutions reduced the rate of illiterate adults from $17 \%$ in 1950 to $9 \%$ at the beginning of 1970 .
\end{abstract}

\section{Keys Word:}

National Committee; Francoism; illiteracy; adult education; literacy.

1 Dirección para correspondencia (correspondence address):

Alba María López Melgarejo C/Severo Ochoa, nº 11, 2D, cp: 30500, Molina de Segura, Murcia (España). 


\section{Résumé:}

Le 10 mars 1950 a été créé par décret le Comité National de Lutte contre l'analphabétisme dont le but était de réduire le taux d'analphabétisme parmi la population adulte espagnole à travers des conseils provinciaux, municipaux et locaux. Le but de cette étude est de reconstruire le chemin d'attaque de cette institution au cours des années cinquante et soixante à partir des documents publiés au Journal Officiel d'État qui la mentionnent. On trouve deux moments clés au cours de la durée du Comité National. La première de création et de développement de 1950 à 1963 et le deuxième temps défini par la Campagne Nationale contre l'analphabétisme initié en 1963 pour quatre années scolaires. Les efforts de cette organisation ainsi que ceux d'autres institutions ont réduit le taux d'adultes analphabètes de 17\% en 1950 à 9\% au début de 1970 .

\section{Mots-clés:}

Comité National; Franquisme; analphabétisme; éducation des adultes; alphabétisation.

Fecha de recepción: 16-10-2016

Fecha de aceptación: 31-1-2017

\section{Introducción}

El analfabetismo nos evoca a un problema del pasado pero hoy España cuenta con 1,9\% de población analfabeta ${ }^{2}$. Para su reducción han sido necesarias acciones de índole educativa junto al apoyo político y económico de los gobiernos estatales desde la segunda mitad del siglo XIX a la actualidad.

El momento en el que surge el interés de que la población española cuente con unos contenidos mínimos educativos, concretamente leer y escribir es a través del Informe Quintana pero será con la Ley Moyano en 1857 cuando esta postura sea realmente apoyada y defendida por las autoridades competentes. La instauración de la obligatoriedad de la escolarización a los menores de edad entre los seis y nueve años supone el inicio de este proceso que frena el crecimiento de analfabetos en España.

El presente estudio indaga y profundiza en la tarea abordada por la Junta Nacional Contra el Analfabetismo al mismo tiempo que reflexiona sobre su actividad, sus éxitos y fracasos. Fue creada por decreto en 1950 durante la vigencia de la Dictadura del General Francisco Franco en pro del desarrollo económico de la nación dado que una "mayor educación proporciona más "capital humano" (socialización, conocimientos y certificados) a los miembros de la sociedad para competir por los puestos y

2 Dicha información ha sido obtenida a través del Instituto Nacional de Estadística a diciembre de 2015. Véase: http://www.ine.es/jaxi/Datos.htm?path=/t42/p03/ I0/\&file=03001.px 
los ingresos" (Bazdresch, 2006, p.68). Su deber fue establecer las pautas para promover "la creación de campañas contra el analfabetismo en todo el territorio nacional, dado el bajo nivel cultural de la población española" (Sóto, 2009, p.128). Las publicaciones del Boletín Oficial del Estado nos han permitido reconstruir la historia de cómo se forjó, implantó y desarrolló a lo largo de sus dos décadas de vigencia.

\section{El analfabetismo en España}

Los censos en torno a las tasas de analfabetos arrojan diferentes porcentajes en función de su autoría. Viñao (1984, p.151) indica que en 1850 el $75 \%$ de la población española era analfabeta, en 1900 el 50\%, en 1930 el 30\% y en 1959 el 15\%. Estos datos son muy aproximados a los ofrecidos por Vilanova y Moreno (1992, p.167) para quienes, en 1900 España contaba con una tasa de analfabetos del 59\%, viéndose reducida al $32 \%$ en 1930 y a un $17 \%$ en los cincuenta.

El término analfabetos abarca a aquellos considerados semianalfabetos. La diferencia entre ambos grupos radica en que mientras los primeros no saben ni leer ni escribir, los segundos sabiendo leer no poseen conocimientos acerca de la escritura. En palabras de Viñao "no hay un único proceso de alfabetización sino dos procesos con evolución diferenciada: el de la difusión de la lectura y el de la difusión de la escritura" (1984, p.157).

En los cincuenta, con una tasa del $17 \%$ de analfabetos, el gobierno nacional precisa detectar cuáles son los motivos de este porcentaje tan elevado respecto a los datos con los que contaban otros países europeos. La situación en España variaba en razón del territorio, siendo mayor el número de analfabetos en las provincias del sur frente a las del norte del país.

No se puede dar solamente una razón que justifique esta realidad sino una serie causas que en su conjunto agravaban el problema. Entre ellas: la falta de escuelas, el medio físico, la dispersión demográfica, una asistencia escolar deficiente, restricciones económicas o la falta de maestros.

Respecto a la falta de escuelas, Guzmán (1955, p.31) informa que "las 17.429 escuelas que existían en 1920 pasan a ser 57.525 treinta años más tarde correspondiendo en ambos momentos, 13,17 y 20,5 centros 
de enseñanza primaria por cada 10.000 habitantes". Estos datos revelan que la escasez de recursos no podía dar respuesta a las necesidades educativas de los menores.

El déficit de centros de Enseñanza de Primeras Letras provocaba que aquellos que no accedían por falta de plaza u otra razón estuviesen abocados a la condición de analfabetos o semianalfabetos por falta de una instrucción básica. Aun así, el aumento de centros educativos construidos durante la primera mitad del XIX no fue suficiente para responder a las demandas de la población. El ritmo de construcción de centros escolares era menor a la velocidad con la que aumentaba el crecimiento demográfico en España.

Para haber podido responder con éxito a las necesidades educativas hubiesen sido necesarias la creación de 55.000 centros para que toda la población tuviera acceso a la educación primaria y, consecuentemente, a la lectoescritura.

Entre otras causas, el medio físico junto con la dispersión demográfica contribuyó a dificultar una escolarización eficiente. Las escuelas se situaban en el municipio principal debiendo acudir al centro niños procedentes de aldeas y pedanías colindantes. De manera asidua, las comunicaciones entre los núcleos de población no eran fácilmente transitables especialmente en zonas montañosas. A pesar de la cercanía entre las diferentes poblaciones la falta de medios y conexiones contribuyó al absentismo escolar.

El número de escuelas en zonas rurales siempre fue mayor que en las urbanas al contrario que las tasas de analfabetos, las cuales fueron más elevadas en las primeras. La dispersión demográfica provocó una baja afluencia de alumnos a dichas aulas situación agravada por la utilización de la mano de obra infantil en las épocas de cosecha en las zonas rurales.

Aunque el número de alumnos matriculados crecía cada año, ese dato no se correspondía con los que asistían regularmente a la escuela. Durante el curso escolar 1940/41, solo el $53,1 \%$ de los niños escolarizados acudieron de manera efectiva, siendo la asistencia en centros educativos privados exponencialmente mayor (Guzmán, 1955, p.63).

Por otro lado, el desprestigio que sufría la profesión docente junto con el bajo salario del profesorado provocó que un bajo número de matriculas en las Escuelas Normales. No solo existía en España una escasez de centros, sino también de docentes.

Fueron tres las soluciones para afrontar el problema del analfabetis- 
mo durante los cincuenta (Guzmán, 1955, p.60). La primera, una ordenación de la enseñanza primaria la cual se inició con la Ley de Educación de 1945 y para la que posteriormente se publicaron en 1953 los Cuestionarios Nacionales para la Enseñanza Primaria. La segunda, la detección de las necesidades formativas para realizar una previsión de futuro con el fin de abordar el desarrollo de las instituciones educativas, es decir, saber dónde están y hacia dónde quieren ir. Por último, y a diferencia de las dos anteriores acciones que contaban con un carácter preventivo, se propuso la creación de una campaña de alfabetización de personas adultas para reducir las tasas de analfabetos. En este contexto, el 10 de marzo de 1950 se crea por Decreto la Junta Nacional contra el Analfabetismo.

\section{Metodología}

Este estudio describe y analiza las acciones realizadas por la Junta Nacional contra el Analfabetismo entre 1950 y 1970 a través de las disposiciones publicadas en el Boletín Oficial del Estado. Así pues, se desarrolla dentro del marco empírico de la investigación histórica la cual "se refiere al esfuerzo que se realiza con el propósito de establecer sucesos, ocurrencias o eventos en un ámbito que interesa al historiador" (Grajales, 2002, p.7).

"Las fuentes bibliográficas, (...) nos enfrentan a un extenso y complejo material en el que nada puede ser despreciado aunque si necesita una adecuada selección" (Romero, 2002, pp.211-212). Por ello se han analizado todas las disposiciones publicadas entre 1950 y 1970 que mencionan a la institución y/o su labor. Dichos documentos son fuentes históricas primarias ya que "tienen una relación directa con el tema investigado" (Alted \& Sánchez, 2011, p.81).

Consecuente del carácter cualitativo de las fuentes se ha recurrido al análisis documental para la recogida y análisis de la información. Para Herrero este procedimiento supone "una serie de operaciones destinadas a describir y analizar la información" (1997, p.44). Dulzaides y Molina consideran al análisis documental como una "extracción científicoinformativa, una extracción que se propone ser un reflejo objetivo de la fuente original, pero que soslaya los nuevos mensajes subyacentes en el documento" (Dulzaides \& Molina, 2004, línea). 
Tras la recopilación de las disposiciones, hemos procedido a su ordenación cronológica y al análisis de la información contenida. Esto nos permite conocer los hechos y decisiones que forjaron la estructura, organización y actividad de la Junta Nacional en España. Por tanto, nuestro objetivo último ha sido reconstruir la historia de la institución a través de los documentos analizados.

La información de las disposiciones permite definir un primer momento de la institución de Creación y desarrollo (1950-1962) y otro correspondiente a la Campaña Nacional contra el Analfabetismo (1963-1970). En la Figura 1. Documentos legales de cada periodo de la Junta Nacional figura la relación de las disposiciones analizadas y su periodo asociado:

Tabla 1

Documentos legales de cada periodo de la Junta Nacional

\begin{tabular}{|c|c|c|}
\hline & FECHA & RANGOY TÍTULO DEL DOCUMENTO \\
\hline \multirow{7}{*}{ 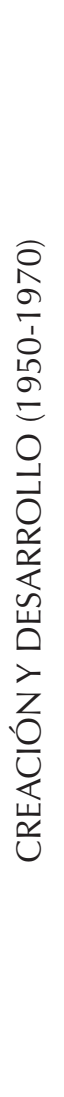 } & $\begin{array}{l}10 \text { de marzo } \\
\text { de } 1950\end{array}$ & $\begin{array}{l}\text { Decreto por el que se crea la Juna Nacional contra } \\
\text { el Analfabetismo. }\end{array}$ \\
\hline & $\begin{array}{l}27 \text { de marzo } \\
\text { de } 1952\end{array}$ & $\begin{array}{l}\text { Orden por la que se dictan las normas para solicitar } \\
\text { subvención para proseguir y fomentar las campa- } \\
\text { ñas emprendidas por la Junta Nacional contra el } \\
\text { analfabetismo. }\end{array}$ \\
\hline & \begin{tabular}{|l|}
8 de julio de \\
1953 \\
\end{tabular} & $\begin{array}{l}\text { Orden por la que se convoca un concurso sobre el } \\
\text { tema: "Causas y remedios del analfabetismo". }\end{array}$ \\
\hline & $\begin{array}{l}20 \text { de julio de } \\
1953\end{array}$ & $\begin{array}{l}\text { Orden por la que se dan normas para las actividades } \\
\text { de las Juntas Provinciales contra el Analfabetismo. }\end{array}$ \\
\hline & $\begin{array}{l}30 \text { de julio de } \\
1953\end{array}$ & $\begin{array}{l}\text { Orden por la que se dan las normas sobre las } \\
\text { campañas que se organicen en la lucha contra el } \\
\text { Analfabetismo }\end{array}$ \\
\hline & $\begin{array}{l}5 \text { de noviem- } \\
\text { bre de } 1953\end{array}$ & $\begin{array}{l}\text { Orden por la que se autoriza la celebración en Ma- } \\
\text { drid de un Cursillo de Comprobación de técnicas } \\
\text { de enseñanza de la lectura y escritura bajo la direc- } \\
\text { ción de la Junta Nacional contra el Analfabetismo. }\end{array}$ \\
\hline & $\begin{array}{l}31 \text { de diciem- } \\
\text { bre de } 1953\end{array}$ & $\begin{array}{l}\text { Orden por la que se aprueba la propuesta del } \\
\text { Jurado Calificador del concurso para adjudicar los } \\
\text { premios concedidos a los mejores trabajos sobre el } \\
\text { tema "Causas y remedios del analfabetismo con in- } \\
\text { dicación de los recursos de todo orden que deben } \\
\text { ponerse en práctica par su extinción, en armonía } \\
\text { con las características geográficas, económicas, } \\
\text { psicológicas y sociales de las distintas regiones y } \\
\text { comarcas españolas". }\end{array}$ \\
\hline
\end{tabular}




\begin{tabular}{|c|c|c|}
\hline & $\begin{array}{l}19 \text { de febrero } \\
\text { de } 1954\end{array}$ & $\begin{array}{l}\text { Decreto por el que se modifica la composición de } \\
\text { la Junta Nacional contra el Analfabetismo. }\end{array}$ \\
\hline & $\begin{array}{l}3 \text { de marzo } \\
\text { de } 1954\end{array}$ & $\begin{array}{l}\text { Orden por la que se dan norma sobre las campañas } \\
\text { que se organicen en la lucha contra el Analfabetis- } \\
\text { mo. }\end{array}$ \\
\hline & $\begin{array}{l}20 \text { de julio de } \\
1954\end{array}$ & $\begin{array}{l}\text { Decreto por el que se amplía la composición de las } \\
\text { Juntas Provinciales y Locales contra el Analfabetis- } \\
\text { mo. }\end{array}$ \\
\hline & $\begin{array}{l}5 \text { de octubre } \\
\text { de } 1955\end{array}$ & $\begin{array}{l}\text { Orden por la que se distribuye } 1.734 .000 \text { pesetas } \\
\text { con cargo al crédito existente de la campaña esco- } \\
\text { lar contra el analfabetismo. }\end{array}$ \\
\hline & $\begin{array}{l}12 \text { de noviem- } \\
\text { bre de } 1955\end{array}$ & $\begin{array}{l}\text { Orden por la que se distribuye } 2.216 .000 \text { pesetas } \\
\text { para atenciones de la Junta Nacional contra el } \\
\text { Analfabetismo. }\end{array}$ \\
\hline & $\begin{array}{l}25 \text { de sep- } \\
\text { tiembre de } \\
1958\end{array}$ & $\begin{array}{l}\text { Orden por la que se resuelve el cursillo de compro- } \\
\text { bación de Técnicas rápidas para la enseñanza de la } \\
\text { lectura y escritura. }\end{array}$ \\
\hline & $\begin{array}{l}22 \text { de agosto } \\
\text { de } 1960\end{array}$ & $\begin{array}{l}\text { Orden por la que se nombra Vocal de la Junta Na- } \\
\text { cional contra el Analfabetismo al Jefe Nacional del } \\
\text { Sindicato Español Universitario. }\end{array}$ \\
\hline 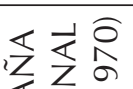 & $\begin{array}{l}10 \text { de agosto } \\
\text { de } 1963\end{array}$ & $\begin{array}{l}\text { Decreto } 2124 / 1963 \text { sobre lucha contra el analfabe- } \\
\text { tismo. }\end{array}$ \\
\hline 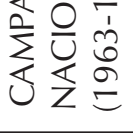 & $\begin{array}{l}28 \text { de octubre } \\
\text { de } 1963\end{array}$ & $\begin{array}{l}\text { Resolución de la Dirección General de Enseñanza } \\
\text { Primaria por la que se organizan los servicios de la } \\
\text { Campaña Nacional de Alfabetización. }\end{array}$ \\
\hline
\end{tabular}

\section{Resultados}

\subsection{Creación y desarrollo (1950-1962)}

\subsubsection{CREACIÓN DE LA RED ORGANIZATIVA}

Tras casi once años después de instaurarse la dictadura del General Francisco Franco y tras haber realizado diferentes políticas y medidas educativas como la promulgación de la ley de educación de 1945, la "depuración" de los maestros que no eran afines al régimen, el establecimiento de presupuestos para la creación de 30.000 escuelas de Educación Primaria, llegaba el momento de afrontar el problema del analfabetismo.

Se necesitaba por parte del gobierno la realización de "una campaña nacional para combatir el analfabetismo, vieja enfermedad que a todo trance se propone eliminar" (Decreto de 10 de marzo, 1950, p.1353). 
Se hizo necesaria la creación de una infraestructura administrativa y educativa para dar respuesta al problema. La Junta Nacional contra el Analfabetismo se creó el 10 de marzo de 1950 por Decreto, dentro de la cartera del Ministerio de Educación Nacional.

Este decreto contó con cuatro artículos. El primero, relacionado con la función que debía cumplir la institución. El segundo, sobre los miembros que conformarían la junta siendo el presidente de la misma el Ministro de Educación Nacional y el vicepresidente el Director General de Enseñanza Primaria. El tercero, estableció la creación de las Juntas Provinciales, Municipales y Locales y, por último, las funciones del Ministro de Educación Nacional como autoridad máxima con competencia para dictar decretos y normas necesarias para garantizar el funcionamiento de la campaña.

La Junta Nacional no tuvo otro fin que la de "redactar las normas convenientes para que se lleve a cabo en diversas regiones españolas una amplia y rápida campaña de extensión cultural que (...) consiga la eliminación del analfabetismo" (Decreto de 10 de marzo, 1950, p.1353). La labor de la institución fue más de gestión que de actuación, pues solamente dictaminó el cómo afrontar la campaña.

Se creó una red de conexión entre la Junta Nacional, la Provincial, la Municipal y, por último, la Local. La información y las normas eran transferidas de unas a otras, pero solo las Juntas Locales se centraron en la aplicación frente a las restantes, que desempeñaron funciones organizativas y burocráticas.

La duplicación de funciones también se realizó en las comisiones que formaron parte de cada una de las juntas. Tanto la Nacional como las Provinciales contaron con una comisión general, formada por miembros de numerosos sectores como la Sección Femenina, la Confederación Católica de padres o el Frente de Juventudes, y una comisión permanente, más reducida, que actuaría en caso de incidencia.

Constituida la Junta Nacional y su organización, se estableció por Orden de 27 de marzo de 1952 las normas para solicitar subvenciones con el objetivo de poder desarrollar las labores pretendidas por la campaña, pudiendo solicitar tales ayudas, no solo las Juntas Provinciales, sino cualquier institución que desempeñase la tarea de alfabetizar. Como desarrolla la orden: "podrán pedirlo también las instituciones del movimiento, las Organizaciones de la Iglesia, y en general, cuantas Entidades vengan dedicándose a esta clase de trabajos" (Orden de 27 de marzo, 1952, p.1652). 
Junto con la solicitud se debía presentar una memoria y un proyecto de actuación en la que se recogerían datos cualitativos y cuantitativos en relación con el número de analfabetos de la zona, así como el de asistentes a las formaciones. Esta información sería clave para otorgar ayudas, pues eran dos los requisitos a partir de los cuales se realizó la distribución. El primero, tendrían prioridad los proyectos que se desarrollaran en zonas donde el número de analfabetos fuera más elevado y, el segundo, aquellas zonas en donde aún no existiesen centros educativos de cualquier tipo.

El control de estas subvenciones fue asumido por delegados nombrados por la Junta Nacional que se encargaron de comprobar que el dinero se invertía donde se señalaba en las memorias presentadas. Además, al finalizar la actividad las diferentes instituciones benefactoras debían enviar a la Junta una memoria con toda la información acerca de la tarea desempeñada.

La función esencial de la Junta fue crear las normas para que el resto de juntas actuasen con el fin de paliar el analfabetismo. Como no se contaba con datos reales de la situación se decidió convocar un concurso bajo el tema "Causas y remedios del analfabetismo". Así, la Junta no debía invertir en investigación al ser los estudiosos de este campo quiénes aportarían la información necesaria y la institución solo debería trazar un plan de trabajo.

Los estudios no debían solamente ajustarse al tema, sino también indicar "los recursos de todo orden que deben ponerse en práctica para su extinción, en armonía con las características geográficas, económicas, psicológicas y sociales de las distintas regiones y comarcas españolas" (Orden de 8 de julio, 1953, p.4402). El plazo para presentar las propuestas finalizó el 30 de noviembre de 1953 y la Junta Nacional, por orden, se asignó la potestad de poder entregar hasta siete premios de diferentes cuantías (3 de 10.000 pesetas, 2 de 5.000 y 2 de 3.000) o, por el contrario, no otorgar ninguno si lo estimaba oportuno.

Los tres premios de 10.000 pesetas fueron para los trabajos: Valoración del analfabetismo en España: Estudio sobre sus causas y remedios de Antonio Guzmán, Causas y remedios del analfabetismo de Santos Gil y Fernando Rodríguez y, el tercero y último, Analfabetismo y Renta de Alfredo Cerrolaza (Orden de 31 de diciembre, 1953, p. 614). Aunque se entregaron otros premios, solo los tres reseñados fueron publicados en el libro "Causas y Remedios del Analfabetismo en España" con autoría conjunta de los ganadores. 


\subsubsection{INICIO DE LA ACTIVIDAD}

Finalmente, por Orden de 20 de julio de 1953, se establecieron las funciones que asumirían las Juntas Provinciales iniciándose la tarea alfabetizadora, pues hasta el momento solamente se había desarrollado la institución y su administración, pero no la actividad. A partir de aquí, fue la comisión permanente de la Junta Provincial la que funcionó como nexo entre ésta y la Junta Nacional y cuya tarea fue "coordinar las actividades de las comisiones locales" (Orden de 20 de julio, 1953, p.4525).

La comisión permanente debía elaborar un plan para toda la provincia especificando qué instituciones iban a formar parte, cuánto dinero era necesario para responder a las necesidades educativas de los analfabetos de la zona, cómo se iban a organizar y a desarrollar las clases de adultos, etc. Este fue el momento álgido de la Junta Nacional, cuando además de teorizar sobre el cómo se inició la campaña.

Se establece la necesidad de crear clases para adultos y adultas, separados por sexos. Se crean escuelas volantes para acudir a aquellas zonas donde no existiesen escuelas nacionales y suplir las necesidades educativas tanto de adultos como de niños. Como dato, se proponen campamentos y escuelas de verano donde de manera intensiva los analfabetos pudiesen rápidamente aprender a leer y escribir.

El Gobierno Nacional financió las diferentes campañas a través de una partida de fondos transferida a las Juntas Provinciales. Los municipios que se beneficiasen de las campañas también deberían colaborar en la subvención de las mismas. Los donativos por parte de particulares eran otra de las fuentes de ingreso, aunque los propios analfabetos también financiarían el proyecto a través de multas que deberían pagar si no asistían a clase y a través de un "arbitrio" impuesto sobre los "analfabetos de uno y otro sexo mayores de quince años, hasta que cada uno de ellos deje de tener tal carácter" (Orden de 20 de julio, 1953, p.4526).

El importe total destinado fue de 3.950 .000 de pesetas, aunque en varias ocasiones se aportaron otras cantidades significativas con el fin de poder afrontar todos los gastos. En 1955 se aprobaron dos partidas presupuestarias: una de 1.734.000 pesetas, destinada en su mayor parte a las Juntas Provinciales con mayores tasas de analfabetos (Orden de 5 de octubre, 1955, p.6920), y otra de 2.216 .000 de pesetas para diversos aspectos como "los gastos de los cursillos", "material fijo y fungible" o "dietas para los miembros de la Junta Nacional, con motivo de visita a los provincias españolas" (Orden de 12 de noviembre, 1955, p.6921). 
El 30 de julio de 1953, se dictó una Orden en relación con las actividades que debían realizar las Juntas Municipales y la Comisión Permanente Local de nueva creación. Se estableció que sería tarea de la Junta Municipal estar en conocimiento de todos los aspectos vinculados al analfabetismo en su municipio. La Comisión Local Permanente, dependiente de la Junta Local, debía informar a la Comisión Provincial de los avances y problemas que surgieran en el proceso de alfabetización de la población, funcionando como nexo entre la verdadera actividad y el gobierno provincial.

Las Juntas Locales estarían, al igual que las provinciales y municipales, formadas por los altos cargos de las diferentes instituciones a las que el problema del analfabetismo afectaba. Entre ellos "el Delegado Local Sindical y el jefe de la Hermandad Local de labradores y Ganaderos, desempeñando la Secretaría Secretario (sic) de la Junta Municipal de Educación" (Decreto de 20 de julio, 1954, p.5720).

En este momento, se decide la creación de un censo de analfabetos elaborado por las Juntas Municipales en el que no solo figure el número con interés estadístico, sino el nombre, edad, domicilio y toda la información que se considere oportuna. Por un lado, las empresas debían informar a la Junta Local de los trabajadores analfabetos que estuvieran a su cargo mayores de doce años y menores de veintiuno. Las administraciones locales y municipales también tenían que dar parte de dicha situación e incluso de aquellos casos dudosos en los que la persona pudiera saber leer pero no escribir.

Esta tarea no solo respondía a una actuación recaudatoria sino "en orden a las campañas futuras, conocer la localización del analfabetismo" (Orden de 30 de julio, 1953, p.5293) de manera que se pudiera actuar más rápidamente en los núcleos con mayor necesidad.

Configuradas las juntas, aprobados los presupuestos y definidos los planes de acción se iniciaba la tarea alfabetizadora en España centrada especialmente en aquellos analfabetos con edades comprendidas entre los doce y los veintiún años.

A lo largo de los siguientes años, la Junta Nacional introdujo cambios en su estructura incluyendo, junto a los representantes de los diferentes sectores laborales y sindicales, a "un representante del Ministerio de Marina, un representante del Ministerio del Aire y el Jefe de Estadística del Ministerio de Educación Nacional" (Decreto de 19 de febrero, 1954, p.1181). La inclusión de representantes de los Ministerios de las Fuerzas 
del Estado se debe a que el servicio militar "ha sido durante casi un siglo el principal instrumento de alfabetización del país en cifras absolutas y relativas" (Puell, 2001, p.308).

Por otro lado, la elaboración de censos por las Juntas Municipales y Locales requería que se valorara y estudiara la información que de los datos cuantitativos y cualitativos se desprendían, estableciendo planes de mejora y señalando las zonas geográficas donde se debía actuar con mayor perseverancia. De aquí, la inclusión del Jefe de Estadística del Ministerio de Educación Nacional en la institución

Por último, el 22 de agosto de 1960, pasó a formar parte de la Junta Nacional en calidad de Vocal, el Jefe Nacional del Sindicato Español Universitario. Como dicta la Orden de 22 de agosto: "El Sindicato Español Universitario ha demostrado su entusiasmo y dedicación a los grandes problemas nacionales y en varias ocasiones los estudiantes en él encuadrados han realizado una espléndida labor de alfabetización en diversas comarcas españolas" (1960, p.12140).

La existencia de la Junta Nacional sufriría modificaciones en la década de los sesenta cuando se trazó a través de dos decretos un nuevo plan que intentarían concluir la labor iniciada en 1950. Según Gastón (1996, p.112), sería 1961 el año que "pondrá colofón a esta etapa y dará paso a las Campañas de Alfabetización y Promoción Cultural implantadas tras los Decretos de la Presidencia de agosto de 1963 y del Ministerio de Educación Nacional de julio del mismo año".

\subsubsection{Cursillo de COMProbación DE téCNiCAS DE ENSEÑANZA DE LA LECTURA Y ESCRITURA}

Por Orden de 5 de noviembre de 1953 se publicó la normativa para la participación en unas jornadas que se celebraron en Madrid con el objetivo de consensuar "los procedimientos de enseñanza de la lectura y la escritura que deban ser divulgados por todo el ámbito nacional y empleados en las campañas contra el analfabetismo" (1953, p.7733) debido a su alta calidad pedagógica. Las diferentes disposiciones emplean de manera indistinta los términos concurso, cursillo o jornadas para referirse a la actividad.

Las personas que tras haber presentado una memoria en torno al método implementado que hubiese conllevado "modificaciones sustantivas en las técnicas de enseñanza del valor y uso de los signos alfabéticos" (Orden de 5 de noviembre, 1953, p.7732), serían los que acudirían a 
Madrid para poner en práctica su método a un grupo de analfabetos. Posteriormente, la Junta Nacional valoraría los puntos fuertes y débiles del proceso empleado y así podrían decidir si era apto para ser desarrollado por norma e implantado en todo el territorio nacional.

En la propia Orden que promueve la actividad se emplean expresiones como "aprendizaje rápido", "en el menor tiempo posible" o "un tiempo notablemente inferior", que muestran la necesidad de acortar plazos y relegando a un segundo plano el aprendizaje en sí mismo.

La comisión para la evaluación de los proyectos y las técnicas incide que las buenas prácticas seleccionadas también se emplearían "para la enseñanza de las técnicas instrumentales de la cultura de las Escuelas Primarias" (Orden de 3 de marzo, 1954, p.1871). De los veintinueve proyectos presentados, diez pasaron la fase de puesta en práctica que tuvo lugar en Colmenar Viejo del 21 de mayo al 21 de junio de 1958.

Tras cinco años de evaluaciones, la Junta Nacional proclamó los métodos de Don Marcos Laseda, Don Antonio Avalos y Don Antonio Calvo como los aconsejados aunque no con carácter obligatorio, como en un primer momento se indicó en la Orden de 25 de septiembre de 1958.

\subsection{Campaña Nacional contra el analfabetismo (1963-1970)}

Los sesenta se iniciaron con una tasa de analfabetos del 14\%, un 3\% menos que al inicio de la década anterior. El porcentaje era mayor en mujeres que hombres (18\% población femenina frente al $9 \%$ masculina). La Junta Nacional señala que gracias a su labor "el número total de adultos alfabetizados entre 1950 y 1962 se elevó a 650.000" (Puell, 2001, p.313). Siguiendo a Puell, estos datos son calificados de "globales, propagandísticos y por tanto medianamente fiables" (2001, p.313) al contribuir a tal fin otras instituciones como el Frente de Juventudes de la Falange y el Servicio Militar.

Son dos los documentos legales que marcarían las directrices para acabar con el analfabetismo en España. Por un lado, el Decreto de 2124/1963, de 10 de agosto, sobre lucha contra el analfabetismo y, por otro, la Resolución General de Enseñanza Primaria por la que se organizan los servicios de la Campaña Nacional de Alfabetización. Esta campaña dejaba a un lado la celeridad del proceso de alfabetización frente al objetivo de desarrollar "la real capacidad de lectura, asimilación, reelaboración y expresión por escrito de lo leído" (Decreto 2124/1963 de 
10 de agosto, 1963, p.13052). Para poder promoverla se crea la Tarjeta de Promoción Cultural de la que deberían estar en posesión los analfabetos que estuvieran en proceso de formación. La población debería poseer la Tarjeta o el Certificado de Estudios Primarios o de lo contrario no tendrían acceso a ciertos "privilegios".

Aquellos analfabetos que no tuvieran la Tarjeta de Promoción Cultural, es decir, no estuvieran intentando suplir sus carencias educacionales a partir de las campañas, no podrían acceder a los campamentos donde se llevaba a cabo la tarea alfabetizadora, obtener pasaporte o licencias de caza o pesca, recibir pagos u obtener préstamos, optar a ayudas económicas o indemnizaciones, percibir prestaciones económicas de la Seguridad Social, así como obtener ayudas escolares para los menores que estuvieran a su cargo.

Igualmente, para que un analfabeto fuese contratado por un empresario debía poseer la Tarjeta de Promoción Cultural, siendo imposible su contratación en caso de no tenerla. Se incentivaba así que los analfabetos se esforzasen en aprender a leer y escribir. Asimismo, no estar en posesión del Certificado de Estudios Primarios prohibía el derecho al voto, el acceso al Servicio Militar de manera voluntaria, ejercer un cargo público, establecer contratos laborales o acceder a cualquier formación oficial.

En 1963 se amplía la ratio de edad de interés para suplir las carencias formativas de los analfabetos. El artículo noveno del Decreto 2124/1963 (1963, p.13053) dictamina que "los analfabetos mayores de catorce años que no tenga más de sesenta, si se trata de varones, o de cincuenta cuando se trate de mujeres, estarán obligados a tomar parte en las campañas de alfabetización de adultos (...)". Otra de las restricciones señalaba que los analfabetos que estuvieran cumpliendo el servicio militar no podrían disfrutar de permisos mientras no demostraran mejoras en sus habilidades en lectoescritura.

Mientras que el Decreto 2124/1963 establecía las obligaciones y deberes de la población analfabeta en relación con la Campaña Nacional, la Resolución de la Dirección General de Enseñanza se centraba en los aspectos burocráticos, de administración y de gestión. En este último, se indica el objetivo de la nueva campaña: "elevar el nivel mínimo de cultura de todos los españoles a las exigencias del Certificado de Estudios Primarios" (Resolución de 28 de Octubre, 1963, p.15296).

Esta década se cerraba con éxito y avances significativos comparados 
con los obtenidos en los diez años anteriores al situarse la tasa de analfabetos en un $9 \%$ ( $5 \%$ en los hombres y en las $12 \%$ mujeres) (Vilanova \& Moreno, 1992, p.167).

\section{Conclusiones}

La labor de la Junta Nacional contra el Analfabetismo junto con las tareas realizadas por otras instituciones situó la tasa nacional de analfabetos en un 9\% en 1970 frente al 17\% existente en 1950. Estos resultados varían en función del territorio, siendo mayor la reducción en las provincias que inicialmente contaban con tasas más elevadas dada la mayor inversión de recursos destinados por parte de la institución ${ }^{3}$.

Las decisiones y acciones de la Junta Nacional variaron en razón del momento. En un primer periodo, de Creación y desarrollo, la prioridad del gobierno se centró en paliar el analfabetismo entre la población más joven. Sería a partir de 1963, con la organización de una nueva Campaña Nacional, cuando el Estado fomenta que sus ciudadanos de hasta sesenta años en el caso de los varones y cincuenta en el de las mujeres, junto a las enseñanzas de lectoescritura adquirieran una formación cultural mínima, dando lugar a un segundo periodo más ambicioso.

En primera instancia, la institución se centró en su creación y desarrollo. El gobierno, tras finalizar varios asuntos pendientes, acometió acciones en relación con la formación adulta. Los tiempos para la creación de la Junta Nacional se dilataron retrasando el inicio de la práctica formativa hasta 1953. Tres años se necesitaron para crear la Junta Nacional y su red de actuación.

No solo el tiempo ralentizó la puesta en marcha de la actividad. La transferencia de competencias entre cuatro órganos diferentes entorpe-

3 Evolución porcentual de las tasas de analfabetos en las distintas provincias españolas entre 1950 y 1970 (Vilanova \& Moreno, 1992, pp.190-191): Álava 2-2; Albacete 3214; Alicante 20-11; Almería 29-15; Asturias 4-4; Ávila 13-7; Badajoz 33-15; Baleares 19-10; Barcelona 9-6; Burgos 4-3; Cáceres 23-13; Cádiz 27-14; Canarias 28-13; Cantabria 4-2; Castellón 22-11; Ciudad Real 33-18; Córdoba 31-16; La Coruña 169; Cuenca 27-15; Gerona 11-7; Granada 32-15; Guadalajara 14-7; Guipúzcoa 4-2; Huelva 29-16; Huesca 12-6; Jaén 37-18; León 6-4; Lérida 10-6; Lugo 14-11; Madrid 7-4; Málaga 34-15; Murcia 27-14; Navarra 5-3; Orense 16-10; Palencia 5-3; Pontevedra 17-9; La Rioja 7-4; Salamanca 6-4; Segovia 5-3; Sevilla 27-15; Soria5-4; Tarragona 15-9; Teruel 17-10; Toledo 25-14; Valencia 14-9; Valladolid 8-4; Vizcaya 4-2; Zamora 9-5; Zaragoza 11-6. 
ció la labor. Una continua exigencia de memorias, informes y resultados para que las auditorias estuvieran al tanto frenaron el proceso de alfabetización, acarreando un gasto excesivo que supuso un cuarto de los presupuestos.

La imposición de un impuesto municipal a los analfabetos no fue suficiente para promover la erradicación del analfabetismo en este momento. Entre otros motivos que frenaron la reducción de la tasa fue que la tarea se centró inicialmente en la población analfabeta de doce a veintiún años.

El continuo nombramiento de responsables de diversas instituciones nacionales que conformarían la Junta durante los primeros años de su existencia manifiesta que el analfabetismo se concibió como un problema que afectaba a gran parte de los sectores de la sociedad.

La segunda fase comprendida entre 1963 y 1970, una vez establecidas las bases administrativas y laborales, supuso que los resultados fueran más positivos en este periodo. Con el decreto 2124/1963 de 10 de agosto de 1963 que fijó las pautas para acometer la nueva Campaña Nacional, se promovieron acciones derivadas del aprendizaje obtenido de la práctica realizada por la Junta Nacional durante la década anterior, centrándose en la enseñanza en sí misma en vez de en aspectos burocráticos y de gestión.

Las medidas propuestas durante los cincuenta no fueron suficientes para que la población acudiera a los centros de formación, por ello se vieron endurecidas, estableciendo como obligación que debían alfabetizarse aquellas personas que no supieran leer o escribir de una ratio de edad mucho más amplio que durante el primer momento. Este periodo fue más ambicioso y abarcó la población adulta de hasta sesenta años en el caso de los hombres y cincuenta en el de las mujeres, pretendiendo, no solo un aprendizaje elemental, sino una formación cultural mínima.

Ambas etapas, diferentes en cuanto a gestión y desarrollo, persiguieron un mismo fin: la reducción de la tasa de analfabetismo. Un país como España que intentaba mostrarse a los ojos de Europa como un país poderoso no podía contar dentro de sus fronteras con un cuarto de la población analfabeta. La reducción fue significativa aunque no total. El proceso fue lento consecuencia directa de una inversión económica insuficiente. La dispersión geográfica de algunas zonas rurales donde las tasas de analfabetos eran muy altas provocaba que las escuelas volantes tuvieran que realizar más campañas no pudiendo unificar a ciertas 
poblaciones por la distancia que había entre unas y otras. Todos estos aspectos contribuyeron a frenar la tarea aumentando el gasto público.

La Junta Nacional contra el Analfabetismo fue una institución, que con sus errores y sus fortalezas, marcó un hito importante en la educación española. La institución consiguió alfabetizar a casi dos millones de adultos en nuestro país entre 1950 y 1970.

\section{Referencias bibliográficas}

Alted, A., \& Sánchez, J. (2011). Métodos y técnicas de investigación en historia moderna e historia contemporánea. Madrid, España: Editorial universitaria Ramón Areces.

Bazdresch, M. (2006). Educación y pobreza: una relación conflictiva. En A. Ziccardi (eds.). Pobreza, desigualdad social y ciudadanía. Los límites de las políticas sociales en América Latina (pp. 65-81). Buenos Aires, Argentina: CLACSO.

Ministerio de Educación Nacional. (1963). Decreto 2124/1963, de 10 de agosto. Decreto sobre lucha contra el analfabetismo. Publicado en Boletín Oficial del Estado No.213, del 5 de septiembre de 1963. España.

Ministerio de Educación Nacional. (1950). Decreto de 10 de marzo. Decreto por el que se crea la Junta Nacional contra el analfabetismo. Publicado en Boletín Oficial del Estado No.90, del 31 de marzo de 1950. España.

Ministerio de Educación Nacional. (1954). Decreto de 19 de febrero. Decreto por el que se modifica la composición de la Junta Nacional contra el Analfabetismo. Publicado en Boletín Oficial del Estado No.61, del 2 de marzo de 1954. España.

Ministerio de Educación Nacional. (1954). Decreto de 20 de julio. Decreto por el que se amplía la composición de las Juntas Provinciales y Locales contra el Analfabetismo. Publicado en Boletín Oficial del Estado No.231, del 19 de agosto de 1954. España.

Dulzaides, M. E., \& Molina, A. M. (2004). Análisis documental y de información: dos componentes de un mismo proceso. Revista Cubana de información en Ciencias de la Salud, 2(12), 1-5. Recuperado de http://scielo.sld.cu/pdf/aci/v12n2/aci11204.pdf .

Gastón, O. (1996). Las campañas de alfabetización y de promoción cultural de las personas adultas en navarra durante el franquismo (1950-1970). En J. Hernández \& A. López (eds.). Cambio Social y Formación Permanente (pp. 109-120). Getafe, España: Impresos y Revistas S.A.

Grajales, T. (Enero-Diciembre, 2002). La metodología de la investigación histórica: una crisis compartida". Enfoques, 14 (1), 5-21.

Guzmán, A. (1955). Valoración del analfabetismo en España. Estudios obres sus causas y remedios. En A. Guzmán, S. Gil, F. Rodríguez \& A. Cerrolaza (eds.). Causas y Remedios del Analfabetismo en España (pp. 9-79). Madrid, España: Publicaciones de la Junta Nacional contra el analfabetismo. Ministerio de Educación Nacional.

Herrero, C. (Enero-Diciembre, 1997). La investigación en análisis documental. Educación y Biblioteca, 83, 44-46.

Ministerio de Educación Nacional. (1955). Orden de 12 de noviembre. Orden por la 
La Junta Nacional contra el analfabetismo (1950-1970): un análisis documental

que se distribuye 2.216.000 pesetas para atenciones de la Junta Nacional contra el Analfabetismo. Publicada en Boletín Oficial del Estado No.320, del 16 de noviembre de 1955. España.

Ministerio de Educación Nacional. (1953). Orden de 20 de julio. Orden por la que se dan normas para las actividades de las Juntas Provinciales contra el Analfabetismo. Publicada en Boletín Oficial del Estado No.206, del 25 de julio de 1953. España.

Ministerio de Educación Nacional. (1960). Orden de 22 de agosto. Orden por la que se nombra Vocal de la Junta Nacional contra el Analfabetismo al Jefe nacional de Sindicato Español Universitario. Publicada en Boletín Oficial del Estado No.207, del 29 de agosto de 1960. España.

Ministerio de Educación Nacional. (1958). Orden de 25 de septiembre. Orden, por la que se resuelve el cursillo de comprobación de Técnicas rápidas para la enseñanza de la lectura y la escritura. Publicada en Boletín Oficial del Estado No.263, del 3 de noviembre de 1958. España.

Ministerio de Educación Nacional. (1952). Orden de 27 de marzo. Orden por la que se dictan las normas para solicitar subvención para proseguir y fomentar las campañas emprendidas por la Junta Nacional contra el Analfabetismo. Publicada en Boletín Oficial del Estado No.102, del 11 de abril de 1952. España.

Ministerio de Educación Nacional. (1954). Orden de 3 de marzo. Orden por la que se nombra una Comisión para la realización del cursillo de comprobación de técnicas rápidas para la enseñanza de la lectura y la escritura. Publicada en Boletín Oficial del Estado No.86, del 27 de marzo de 1954. España.

Ministerio de Educación Nacional. (1953). Orden de 30 de julio. Orden por la que se dan normas sobre las campañas que se organicen en la lucha contra el Analfabetismo. Publicada en Boletín Oficial del Estado No.246, del 3 de septiembre de 1953. España.

Ministerio de Educación Nacional (1953). Orden de 31 de diciembre. Orden por la que se aprueba la propuesta del Jurado Calificador del concurso para adjudicar los premios concedidos a los mejores trabajos sobre el tema "Causas y remedios del analfabetismo con indicación de los recursos de todo orden que deben ponerse en práctica para su extinción, en armonía con las características geográficas, económicas, psicológicas y sociales de las distintas regiones y comarcas españolas". Publicada en Boletín Oficial del Estado No.32, del 1 de febrero de 1954. España.

Ministerio de Educación Nacional. (1953). Orden de 5 de noviembre. Orden por la que se autoriza la celebración en Madrid de un Cursillo de Comprobación de técnicas de enseñanza de la lectura y la escritura bajo la dirección de la Junta Nacional contra el Analfabetismo. Publicada en Boletín Oficial del Estado No.363, del 29 de diciembre de 1953. España.

Ministerio de Educación Nacional. (1955). Orden de 5 de octubre de 1955. Orden por la que se distribuye 1.734 .000 pesetas con cargo al crédito existente de la campaña escolar contra el analfabetismo. Publicada en Boletín Oficial del Estado No.320, del 16 de noviembre de 1953. España.

Ministerio de Educación Nacional. (1953). Orden de 8 de julio de 1953. Orden por la que se convoca un concurso sobre el tema: "Causas y remedios del analfabetismo". 
La Junta Nacional contra el analfabetismo (1950-1970): un análisis documental

Publicada en Boletín Oficial del Estado No.201, del 20 de julio de 1953. España.

Puell, F. (Enero-Diciembre, 2001). Educación de adultos en el Servicio Militar Español. Historia de la Educación, 20, 307-331.

Ministerio de Educación Nacional. (1963). Resolución de la Dirección General de Enseñanza Primaria por la que se organizan los servicios de la Campaña Nacional de Alfabetización. Publicada en Boletín Oficial del Estado No.258, del 28 de octubre de 1963. España.

Romero, J. (Enero-Diciembre, 2002). Presupuestos básicos para la investigación histórica-educativa". XXI Revista de Educación, 4, 203-216.

Sóto, J. (Enero-Diciembre, 2009). Campañas de alfabetización rural en Extremadura: Cañamero. Alcántara, 70, 125-141.

Vilanova, M., \& Moreno, X. (1992). Atlas de la evolución del analfabetismo en España de 1887 a 1981. Madrid, España: Gráficas Juma.

Viñao, A. (Enero-Diciembre, 1984). Del analfabetismo a la alfabetización. Análisis de una mutación antropológica e historiográfica. Revista Interuniversitaria Historia de la Educación, 3, 151-190. 
